\title{
Transversalidade e Tecnologias de Informação e Comunicação ensinando Química utilizando um ambiente virtual com tema gerador Água
}

\section{Resumo}

\author{
Maria Helena Pamplona: \\ Clevi Elena Rapkiewicz ${ }^{* * *}$ \\ Maria Cristina Canela****
}

Este projeto utiliza o Ambiente Virtual para o Estudo de Ciências (AVEC) veiculado através da internet, com a finalidade de ensinar Química a partir da Química Ambiental. Esta proposta visa desenvolver um modelo de construção do conhecimento para que o ensino de Química tenha uma melhor fundamentação teórica e que atenda a demanda social por um ensino contextualizado e sintonizado com as necessidades tecnológicas atuais. O ambiente é baseado na metodologia $A B C$ (Aprendizagem Baseada em Casos) e é composto de duas situações-problema relacionadas ao tema Água, sendo que a primeira está direcionada para professores e licenciandos de Química e a segunda para serem usados pelos professores com seus alunos no Ensino Médio. A situação problema enfatiza a escassez de água no planeta e sua poluição, ao mesmo tempo em que ensina Química. O AVEC-Química foi utilizado com licenciandos e professores de Química. O grupo de licenciandos participou ativamente se mostrando motivado e apresentando ao final uma avaliação positiva do ambiente com um aprendizado sobre os temas abordados que permitiram verificar a validade deste ambiente criado para o ensino de Química através da Química Ambiental.

Palavras-chave: Ambiente Virtual de Ensino, Ensino de Química, Informática na Educação
Abstract
This study presents a Virtual Environment for the Study of Sciences (AVEC) developed to teach Chemistry using Environmental Chemistry as a learning background. The goal of this AVEC is to present a knowledge construction model aimed at providing a better theoretical framework capable of fulfilling the social demands for a contextualized teaching process. This AVEC is based on the $A B C$ methodology (learning based on case studies) and it is divided into two case problem scenarios based on the Water theme. The first situation is oriented to attend faculty and students of Chemistry Teacher undergraduate programs and the second is aimed at students of middle and high school levels. The case problem emphasizes the issues of water scarcity and water pollution while teaching Chemistry related topics. The AVEC-Chemistry was applied to faculty and students of a Chemistry teacher's formation undergraduate course. The students showed great interest and were very motivated about participating in the exercise, and their evaluation of the AVEC was positive. In addition, an evaluation of the students performance indicated the occurrence of a good learning level curve on the different themes included in the virtual environment. Therefore, the students performance is regarded as a good validation tool of AVEC-Chemistry. Finally, the result o this study indicate that virtual environment can be useful teachings for sciences.

\footnotetext{
:*Msc. - Universidade do Estado do Norte Fluminense Darcy Ribeiro / CCT - Programa de Pós Graduação em Ciências Naturais - pamplona@uenf.br

:**Prof. Dr. Universidade do Estado do Norte Fluminense Darcy Ribeiro - Laboratório de Engenharia de Produção -

:***Prof. Dr. Universidade do Estado do Norte Fluminense Darcy Ribeiro - Laboratório de Ciências Químicas mccanela@uenf.br clevi@uenf.br 
Keywords: Virtual Environment Teaching, Chemistry Education, Informatic Education

\section{Introdução}

A educação desde a implantação da Lei de Diretrizes e Bases está passando por um processo de renovação. A ampliação desta legislação é encontrada nas novas pedagogias descritas nas diretrizes para o Ensino Médio, expressas no documento do Ministério da Educação através dos Parâmetros Curriculares Nacionais (PCN) e no Programa Sociedade da Informação, do Ministério da Ciência e Tecnologia, que estão impulsionando o desenvolvimento de cursos de formação de professores valorizando o uso das Tecnologias de Informação e Comunicação (TIC).

A escola é considerada, tradicionalmente, uma fonte de cultura e conhecimento. Contudo, as novas diretrizes colocam a escola, também, como fonte de "competências que devem ser adquiridas ou reconhecidas e desenvolvidas" e dentre essas competências se encontra o uso da informática dentro da sala de aula (Alarcão, p.12, 2003).

Sendo assim, é importante valorizar o trabalho do professor utilizando recursos tecnológicos já que a "Educação é o elemento-chave para a construção da sociedade da informação", além de ser necessária de uma forma contínua na vida de qualquer cidadão (Takahashi, p.7, 2000).

$\mathrm{Na}$ integração das inovações da Tecnologia da Informação e Comunicação (TIC) com a área educacional diferentes usos da tecnologia são possíveis, entre eles, os ambientes educacionais via internet. Tais ambientes disponibilizam textos, imagens e sons para estimular a aprendizagem com tarefas e apoio pedagógicos, além da troca de experiências com outras pessoas que estejam usando o mesmo ambiente (Lyra et al., 2003).

Paralelamente, os PCN, direcionados para o Ensino Fundamental, consideram o Meio Ambiente como tema transversal obrigatório, destacando a necessidade de um estudo contextualizado e não-enciclopédico das disciplinas.

Como a Química é considerada uma das disciplinas de grande dificuldade de aprendizagem, e ao mesmo tempo diversos assuntos são tratados nessa ciência, com várias questões e aplicações práticas no dia-a-dia do aluno, a criação e utilização de ferramentas dinâmicas podem auxiliar o ensino-aprendizagem desta disciplina.

Assim, a fim de discutir as aplicações práticas das fundamentações acima citadas e atender a demanda de futuros profissionais da educação que saibam utilizar as TIC, este projeto descreve a utilização do Ambiente Virtual para o Estudo de Ciências (AVEC). A proposta do ambiente é ensinar Química através da Química Ambiental, a partir de Estudos de Casos. Esses casos têm como tema estruturador, Água, que possibilita a interligação dos conteúdos específicos do Ensino de Química. A validação do ambiente foi realizada com os licenciandos do Curso de Química da Universidade do Norte Fluminense Darcy Ribeiro - UENF.

\section{Metodologia}

O ambiente AVEC está dividido em três classes principais interligadas entre si. São elas: i) interação: onde se encontram as ferramentas de comunicação; ii) Ferramentas educacionais disponibiliza conteúdos relativos à disciplina praticada pelo professor, aspectos pedagógicos e tecnológicos e iii) situações-problema: texto que levam a reflexão sobre um problema e as opções de soluções para o problema (Figura 
$1)$.

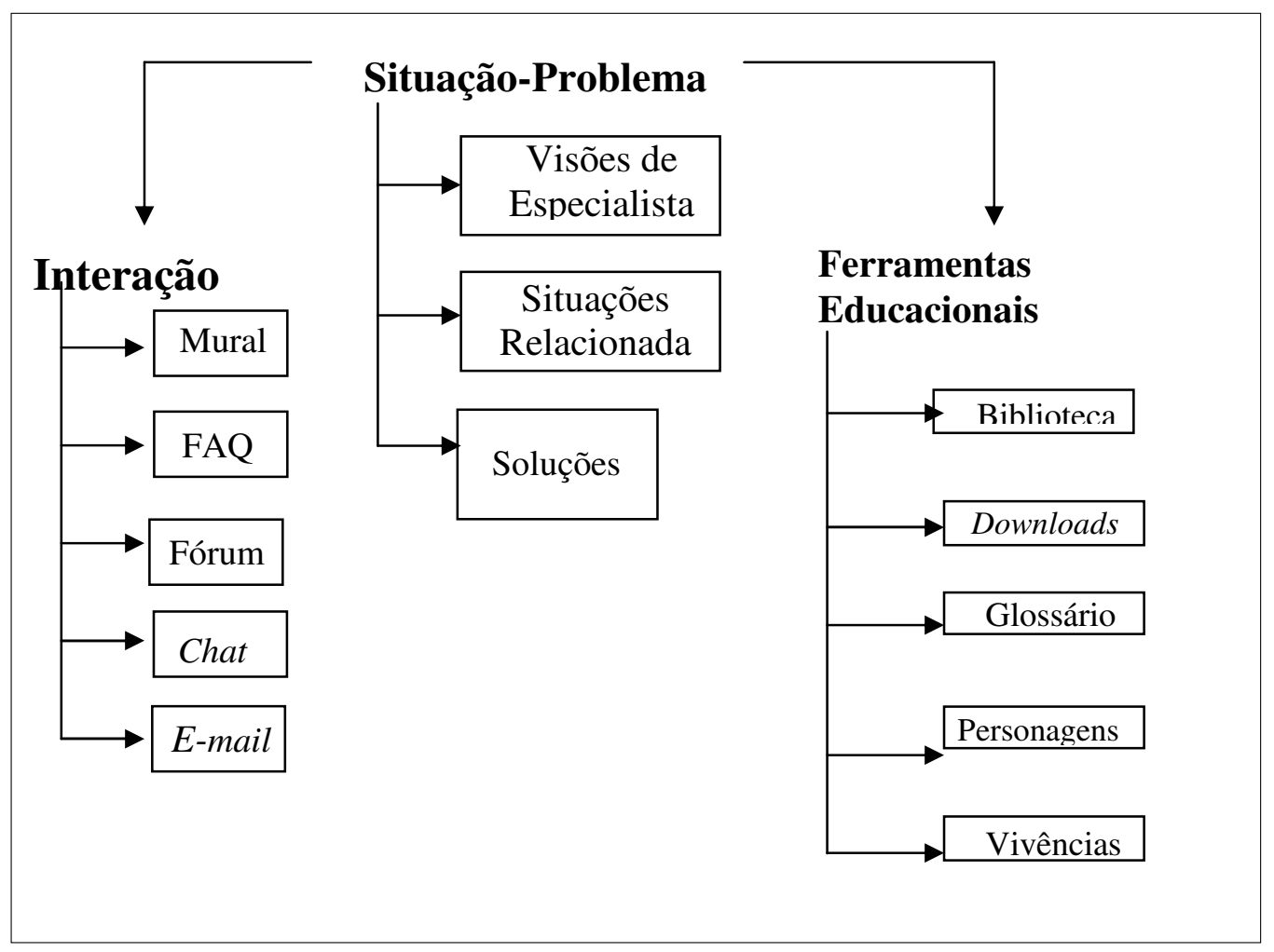

Figura 1 - Esquema do sistema AVEC mostrando suas três classes.

$\mathrm{Na}$ classe, Interação, é possível observar a área de comunicação. Esta área permite troca de mensagens e orientações entre os alunos e tutores de forma on-line, como no chat ou em outro momento qualquer durante o processo de utilização do ambiente, que são os outros itens desta classe (Figura 1-I).

Na classe Ferramentas educacionais, está disponível conteúdos, que de alguma forma ajude o aluno a realizar sua tarefa. Esta área abrange textos de reflexão sobre a Química, divulgação de projetos de professores que deram bons resultados, disponibilidade de material didático em forma de documentos, links ou conteúdos para facilitar a pesquisa dos problemas, pesquisa de termos técnicos, pesquisadores importantes relacionados à Química e história de vida e pesquisas (Figura 1-II).

Enfim, na classe, Situação-Problema, é mostrado a situação em forma de texto onde o aluno tem alguns passos a cumprir.

No ambiente proposto, além das outras classes descritas que poderão ser utilizadas a qualquer momento, o aluno ainda poderá contar com exemplos de problemas e soluções semelhantes ao proposto, além de depoimentos de outros especialistas da área com o objetivo de contribuir para o problema (Figura 1-III).

A modelagem conceitual proposta para este ambiente de aprendizagem com suporte na Internet foi baseada na metodologia ABC - Aprendizagem Baseada em Casos (Struchiner \& Rezende, 1998). Nesta metodologia são propostas situações-problema que sejam as mais próximas possíveis da realidade a fim de direcionar o aluno a pesquisar e propor soluções possíveis para o problema apresentado (Savery \& Duffy, 1995). 
Para cada problema apresentado as seguintes etapas foram cumpridas: i) definir todo o problema apresentado; ii) listar e categorizar os dados que são relevantes; iii) listar as soluções possíveis que vão de encontro aos seus critérios e, iv) listar critérios adicionais e selecionar a melhor solução possível para o problema (Uribe, Klein e Sullivan, 2003).

A situação-problema é proposta para o aluno, contextualizada no formato de texto. A seguir, o aluno entra em um processo ativo de tomar contato com a realidade que o cerca e refletir sobre o assunto a partir do texto proposto. Ao fazer isto, o aluno tem oportunidade de discutir suas opiniões, elaborar hipóteses, rever suas idéias a partir da opinião de terceiros e modificá-la. E, por fim, propõe uma solução sob seu ponto de vista (passo 1). Além disso, este aluno tende a "desenvolver uma postura que conduza à geração de questões e à coleta de informações que o auxiliem para que, ele próprio se torne capaz de definir e conceituar os problemas e persiga soluções compatíveis diante de cada nova situação" (Struchiner \& Rezende, 1998, p.4) (passo 2). Sendo, mais tarde, possível "desenvolver estratégias para identificar as questões de aprendizagem e localizando, avaliando e aprendendo a partir das questões relevantes em questão" (Savery \& Duffy, 1995, p.35) (passo 3).

A estratégia utilizada, direcionada à seção de "Química", é a valorização do conteúdo a partir da discussão de problemas vivenciados pelo professor e pelo aluno no seu dia-a-dia e que estão relacionados com o meio ambiente. Além de mostrar a importância do meio ambiente em condições favoráveis ao ser humano, o efeito nocivo da degradação ambiental, as práticas e as possíveis soluções. $\mathrm{Na}$ figura 2 podemos observar a página principal do ambiente AVEC com suas várias classes de interações.

Deste modo foram propostas duas situações-problema: 1) Água - problema do século XXI e 2) Poluição das Águas. Para cada problema foi estipulado um prazo prédeterminado a ser cumprido através da interação com o ambiente. $\mathrm{O}$ acesso pode ser concretizado no melhor horário para os alunos, mas dentro do prazo estipulado para tal. O problema seguinte só foi disponibilizado ao término do caso anterior. No período de resolução, ocorreu uma reflexão sobre o fato, ou seja, o licenciando pensava sobre a solução proposta e procurava compreender se foi a melhor solução ou não, trocando informações com os outros alunos através do fórum ou chat, acessando a biblioteca ou fazendo downloads para ter um embasamento teórico. Mesmo que a solução proposta fosse a mais adequada, puderam comparar com as respostas de outros licenciandos reformulando, se fosse o caso, sua resposta (Figura 3).

O grupo de licenciandos em Química que participaram das situações-problema no AVEC consistia de alunos do quinto e sétimo período fazendo em comum as disciplinas de Informática na Educação e Química Ambiental, totalizando 22 alunos, com $72,7 \%$ de mulheres e $27,3 \%$ de homens. Para traçar o perfil deste grupo foram aplicados dois questionários, o primeiro, visando analisar o conhecimento dos mesmos na área de informática e o segundo, o grau de conhecimento de alguns tópicos sobre Química Ambiental.

O primeiro fórum e chat realizados foram direcionados as discussões sobre o ambiente AVEC e a informática na Educação. Os fóruns e chats 2 e 3 correspondiam as situações-problemas 1) e 2), respectivamente. A metodologia escolhida para a análise do fórum e do chat, focalizando os usuários durante a utilização do ambiente AVECQuímica foram diferenciadas. Para a análise da seção Chat empregou-se a metodologia do Comunicografo, uma ferramenta de bate-papo (Pimentel, 2002). E para os textos no Fórum, por terem um perfil de discussões mais elaboradas, utilizou-se a Análise da Conversação (Bardin, 1977). 


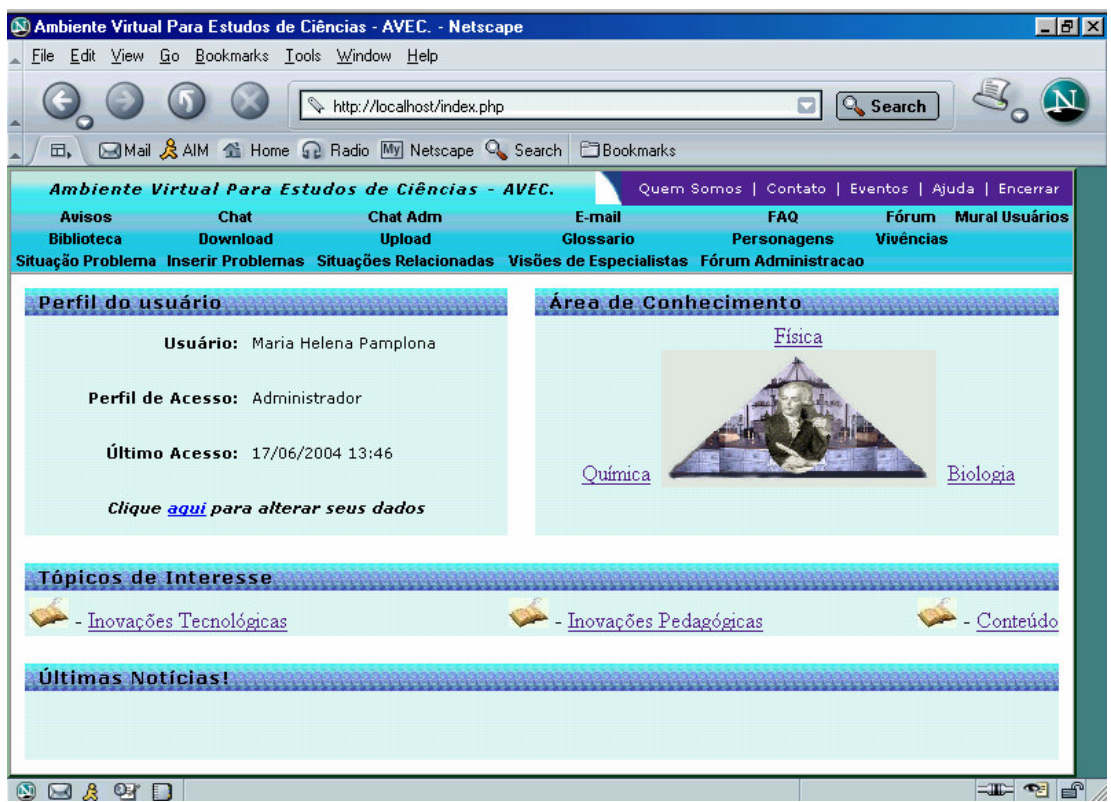

Figura 2: Página inicial do AVEC-Química.
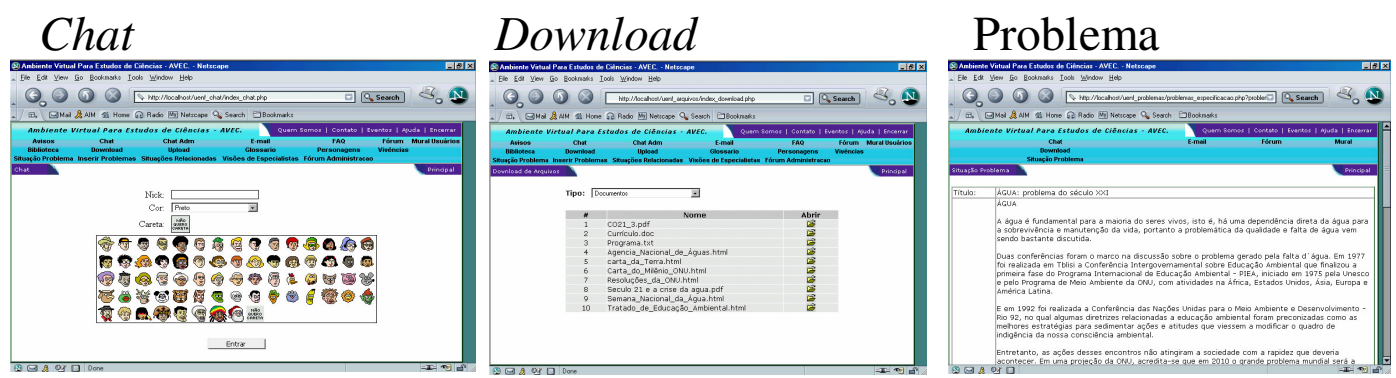

Figura 3: Sessão de Chat (E), de Download (C) e Problema (D).

\section{Resultados e Discussão}

Após a construção do ambiente conforme descrito acima, o mesmo foi aplicado aos alunos do curso de licenciatura em Química. Primeiramente foram obtidos os resultados sobre o perfil dos alunos quanto ao uso de tecnologias e quanto ao conhecimento de tópicos básicos de química. Os resultados dos questionários indicam que quase metade dos alunos possuía computador, mas apenas $40 \%$ tinham acesso à internet. De um modo geral acham importante o uso da ferramenta computacional tanto no cotidiano quanto na confecção de trabalhos para o curso superior usando pacotes de software de escritório como editores de texto, de apresentações e planilhas. Também sabem usar a internet para troca de mensagens e pesquisas em sites, mas poucos usam o chat ou programas de mensagem on-line (25\%). Deste grupo, mais da metade não utiliza software educativo $(62,5 \%)$ e o restante utiliza pouco. Entretanto, a maioria sabe da importância do software educacional na construção do conhecimento e do papel do professor usando esta ferramenta na sala de aula.

Apesar dos licenciandos reconhecerem que tiveram os conteúdos do questionário sobre Química desde o ensino médio e aprofundados no ensino superior, apresentaram V.3 $\mathrm{N}^{\circ} 2$, Novembro, 2005 
dúvidas conceituais ou demonstraram pouco conhecimento da legislação relacionada ao meio ambiente. Mesmo assim, os alunos reconhecem que a Química Ambiental é o estudo dos processos químicos que ocorrem no meio ambiente.

Após a aplicação do ambiente com os alunos, os produtos gerados foram analisados para verificar se o objetivo havia sido alcançado.

- Análise do Chat

O Comunicografo (Pimentel, 2002) tem como finalidade obter uma visão mais objetiva dos tópicos. A característica que dá caráter dinâmico ao chat é a sua sincronicidade, isto é, todos devem estar no mesmo ambiente virtual na mesma hora. Por ser um sistema dinâmico, as mensagens devem ser curtas para facilitar a leitura e troca de mensagens em tempo real.

A análise do chat é feita a partir das interações entre as falas dos participantes e montada as ligações. As mensagens devem indicar três importantes funções: i) coesão, onde uma mensagem pode ou não gerar uma seqüência de outras mensagens; ii) coerência, que consiste da compreensão do texto dentro da situação em que foi escrita e iii) participação, que é a identificação da sequiência de um tópico, reconhecer o início de outro e/ou identificar o encadeamento entre eles.

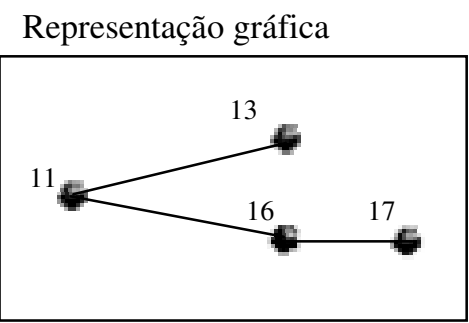

Representação matemática

$\mathrm{V}=\{11,13,16,17,20\}$
$\mathrm{A}=\{(11,13),(11,16)$,
$1 \mathbf{1} \times \mathbf{1 7}$ ।

Figura 4: Exemplo de representação gráfica e uma matemática no Comunicógrafo (PIMENTEL, 2002)

Após revisar por completo o texto originado nos chats identificando os pontos de coesão, coerência e participação, é construída sua estruturação a partir do Comunicografo (Pimentel, 2002). Esta ferramenta é designada por um grafo utilizado para modelar um processo de comunicação. No Comunicografo (Pimentel, 2002), os vértices e arestas são as mensagens e as arestas das associações entre elas (Figura 4). A tradução do texto do chat em uma representação gráfica permite, através da figura de uma árvore ramificada ou não, identificar qual o assunto tratado e sua intensidade no contexto do chat.

Os três chats realizados para discutir as situações-problema propostos resultaram nos grafos, como por exemplo os apresentados na Figura 5 

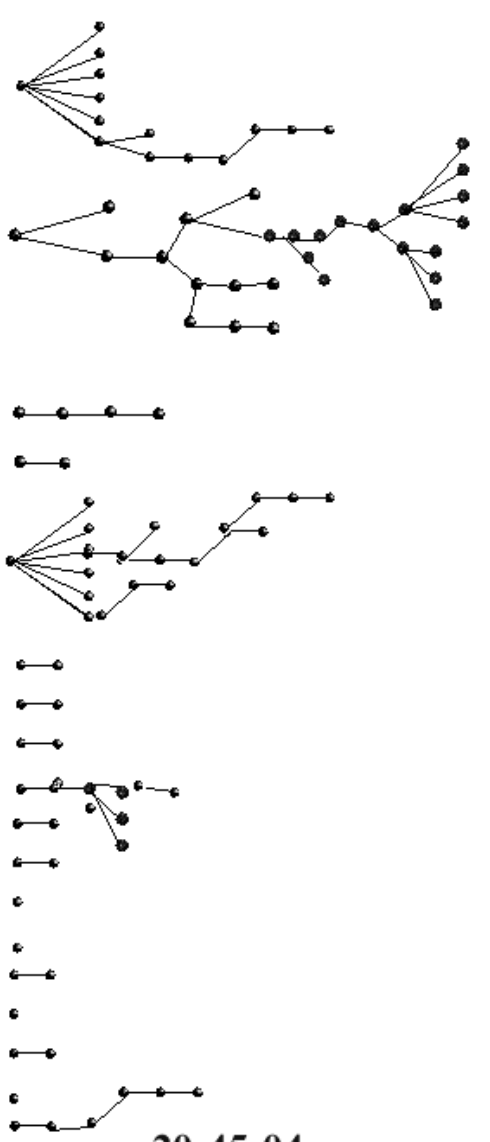

20:45:04

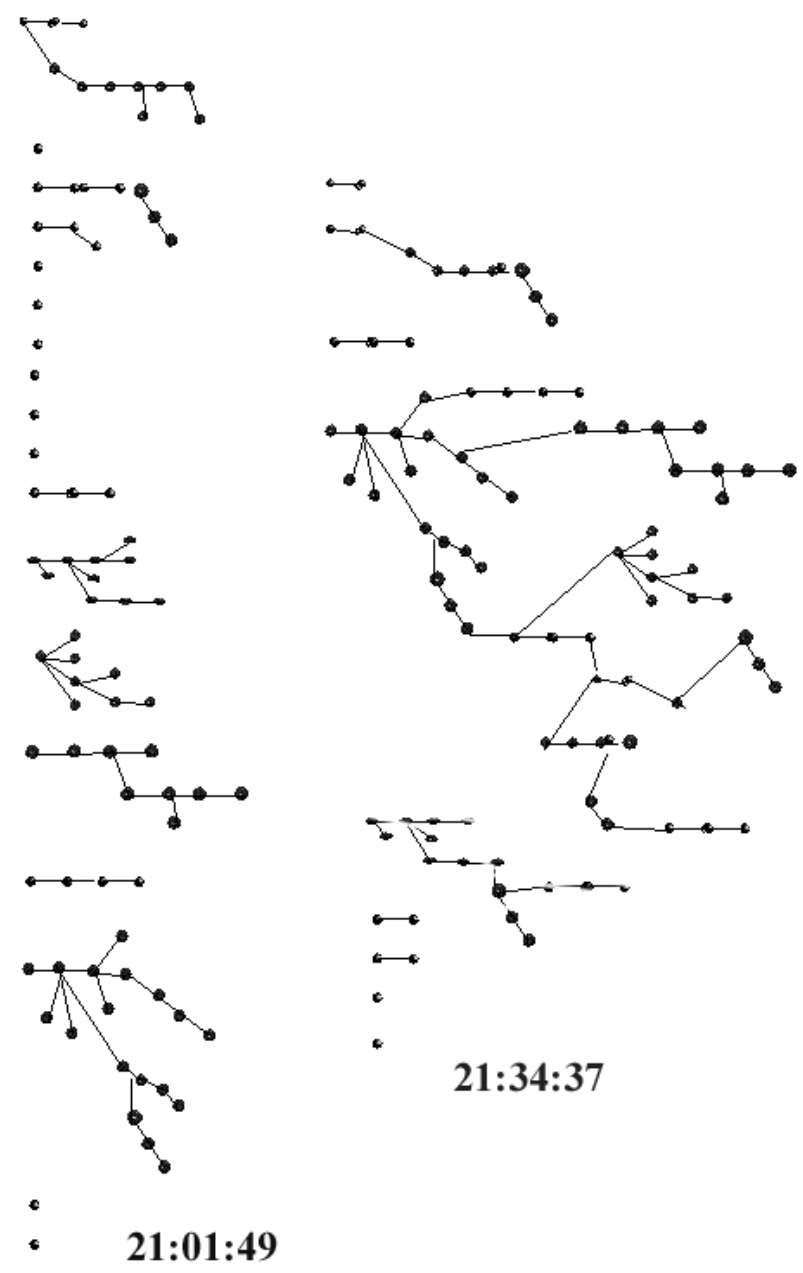

Figura 5: Gráfico resultante do chat ocorrido em 21junho2005

Os assuntos que mais se destacaram nos chats, em um primeiro momento, foram as questões operacionais do ambiente. Nos chats subseqüentes foi destacada e discutida à importância da questão da utilização da informática na educação e a contaminação das águas através da infiltração de contaminantes nas águas subterrâneas e a necessidade de tratamento de águas contaminadas. O Chat da figura 5 é apresentado em árvores menores que indicam que na maioria das vezes ocorreram mensagens pessoais, de outra disciplina ou brincadeira. Nos locais onde são encontradas as folhas, há mensagens que não foram respondidas ou tentativa de mudança de assunto que não encontrou respaldo no grupo.

A análise geral mostrou que além de prevalecer os diálogos para tirar dúvidas do ambiente (primeiro chat deste grupo com presença da maioria), também houve uma intensa discussão sobre a importância do uso da tecnologia na escola e a falta de capacitação dos professores atualmente.

Nos chats seguintes, culminando com o apresentado na figura 6, os assuntos paralelos foram tornando-se mais secundários. Pode-se observar que neste chat há uma grande árvore que se sobressai indicando que o assunto tratado foi, praticamente, debatido por todos, gerando ramificações de discussões convergentes sobre a poluição 
de água, tema do segundo estudo de caso. Os outros assuntos levantados foram a realização dos passos e outros atividades acadêmicas.

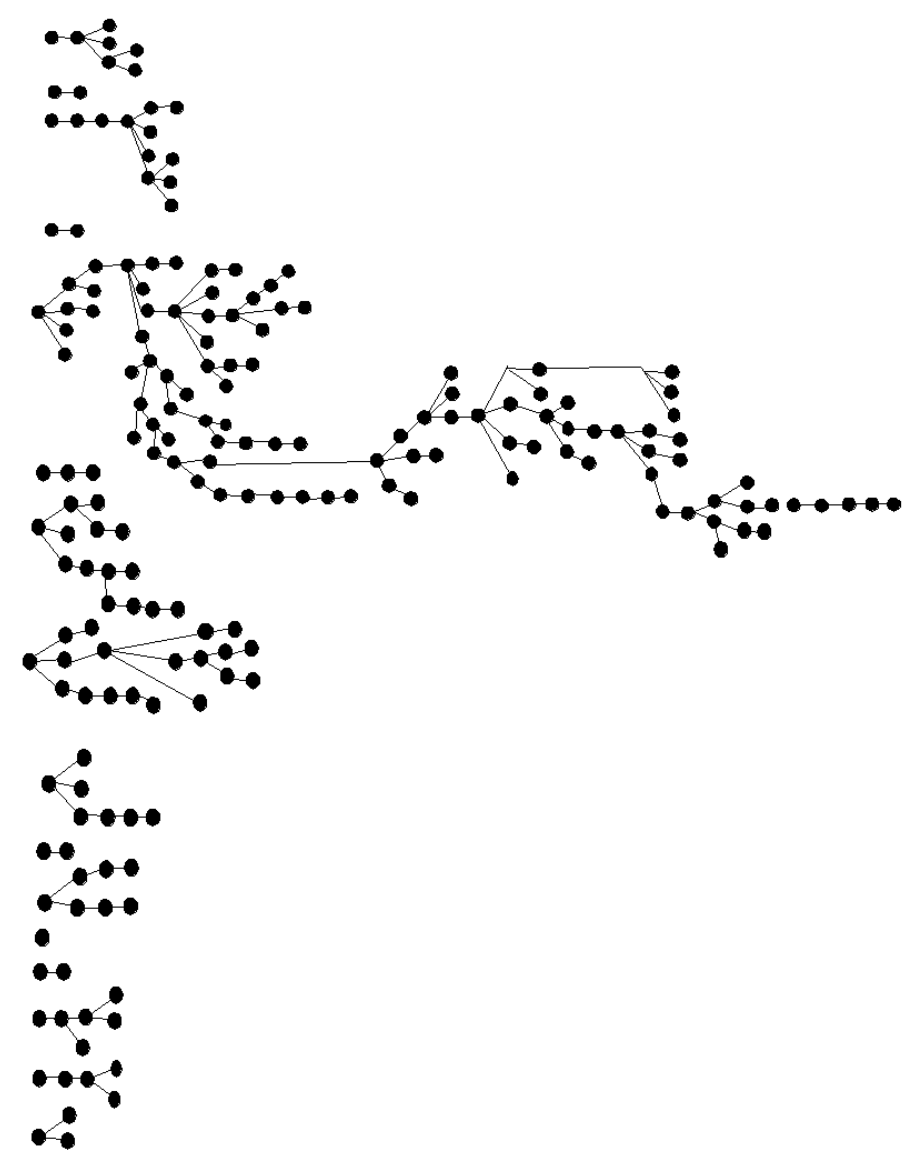

Figura 6: Gráfico resultante do chat ocorrido em 29junho2005

A partir da realização dos chats foi notado que esta sessão do AVEC é um local que proporciona intenso debate e ao mesmo tempo consegue ser uma forma de integração entre os participantes porque dá oportunidade de "(...) conversar com pessoas com quem ainda não conversávamos na turma.(...)“; trocar idéias e opiniões. No Chat foi possível constatar que as discussões modificaram a postura dos participantes do chat.

- Análise do Fórum

Como cada Fórum tem uma pergunta inicial, que dá o start a discussão, esta foi considerada o índice para a análise de todo o texto, isto é, as discussões geradas a partir desta pergunta foram consideradas um documento completo. Deste modo, os textos são codificados, isto é, estruturados de maneira a qualificar melhor o conteúdo escrito.

Para esta técnica, Análise de Avaliação (Bardin, 1994), é necessário um conjunto de elementos como: i) objetos de atitude, que são os elementos do texto que vão ser correlacionados para avaliação e, ii) os termos avaliativos, que correspondem ao predicado com valores positivos e negativos, variando de +3 até -3 , respectivamente.

Para cada inserção nos fóruns é realizado um cálculo obtido com o grau de interesse debatido nas discussões de cada fórum, a soma de todos os produtos obtidos da multiplicação do conector verbal e do termo comum, para em seguida dividi-lo por $3 \mathrm{~N}$, onde 3 é a amplitude da escala e $\mathrm{N}$, o número total de textos avaliados em cada fórum.

A partir dos dados acima, foi montado um gráfico (Figura 7) que melhor

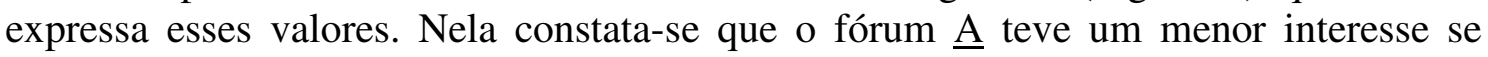


comparada com os outros três fóruns. Os fóruns $\underline{B}$ e $\underline{C}$, tiveram uma pequena diferença entre elas. Já o fórum $\underline{B}$ e $\underline{D}$ foi o que teve melhor colocação dentre os quatro fóruns realizados.

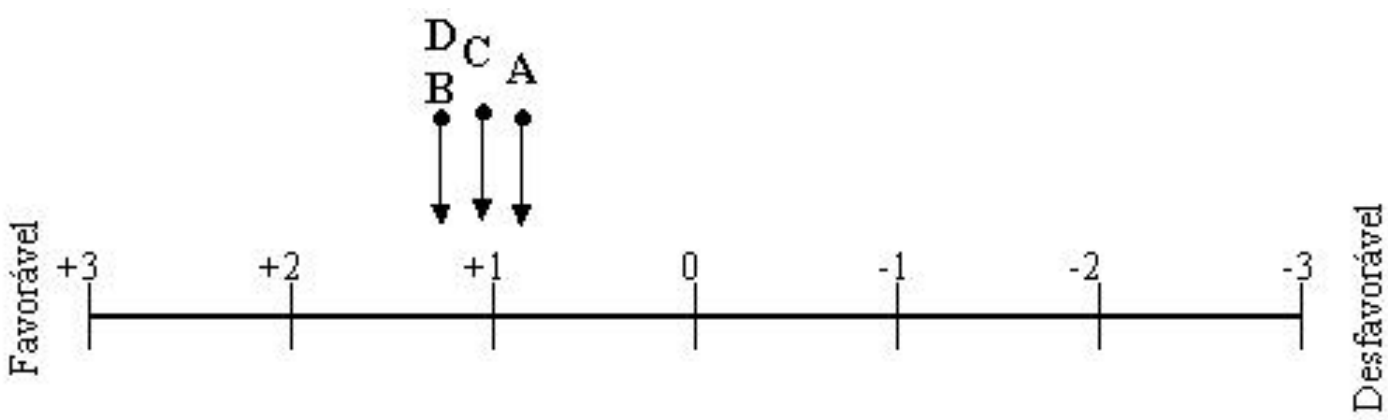

Figura 7: Gráfico dos fóruns realizados indicando o grau de interesse dos alunos pelo debate

\section{CONCLUSÃO}

O desenvolvimento da sessão de Química no AVEC e seus conteúdos abordando a Química Ambiental surge como expectativas de bons resultados entre o Ensino de Química e o uso das TIC, podendo mostrar um ensino contextualizado e com grande ênfase a Educação Ambiental. Os dados obtidos demonstram que o AVEC é um dos caminhos para introduzir os licenciando de Química nos recursos disponíveis através da informática e mostrar que o ensino de Química pode ser feito através do Meio Ambiente de uma maneira simples e didática. A participação dos licenciandos durante a validação foi de média para muito boa, sendo que a sessão do fórum foi importante para desenvolver as atividades propostas no ambiente e também era a mais freqüentada. As sessões de biblioteca, vivências e chat tiveram, segundo a opinião dos alunos, uma participação média. Muitos alunos recorreram a diferentes materiais para a resolução da situação-problema, diferentes dos apresentados na biblioteca.

Nos Estudos de Casos, os licenciandos julgaram os textos bem acessíveis com excelente participação no seu desenvolvimento. Apenas dois alunos disseram que não iriam freqüentar o ambiente nos próximos meses. Os alunos assinalam que este ambiente deveria ser oferecido aos alunos do Ensino Médio e seus professores e que deveria fazer parte das atividades de outras disciplinas da graduação, além de serem utilizados por outros alunos da licenciatura e de outros cursos.

\section{REFERÊNCIAS BIBLIOGRÁFICAS}

ALARCÂO, Isabel. Professores Reflexivos em uma escola reflexiva. São Paulo: Cortez. 2003.

BADIN, L. Análise de Conteúdo. Lisboa: Edições 70. 1977. 225p.

LYRA, A., R.,I.; LEITÃO, D., A.; AMORIM, G., B.C.; GOMES, A., S. Ambiente 9 
virtual para análise de software educativo. In: SOCIEDADE BRASILEIRA DE COMPUTAÇÃO, 23., 2003, São Paulo: UNICAMP.

PIMENTEL, M. G. Hiperdiálogo: uma ferramenta para diminuir a perda do co-texto. Dissertação (Mestrado). Núcleo de Computação Eletrônica (NCE), Universidade Federal do Rio de Janeiro, Rio de Janeiro, 2002.

SAVERY, J. R. \& DUFFY, T. M. Problem based learning: an instrucional model and its constructivist framework. Educational Tecnology. September/october. p. 31-38. 1995.

STRUCHINER, M.; REZENDE, F. Uma proposta de modelo para Ensino baseado em Casos para um ambiente de EAD. Mimeografia, LTC-NUTES, Universidade do Rio de Janeiro, 1998.

TAKAHASHI,T.(org.).Sociedade da Informação no Brasil:Livro Verde.Brasíl a,Ministér o da Ciênc a e Tecnologia.2000.

URIBE, D., KLEIN,J. D., SULLIVAN, H. The Effect of Computer-

Mediated Collaborative Learning on Solving ILL-Defined Problems. Educational Technology Research and Development (ETR\& 